\title{
A new flow behaviour model for the austenite at high temperature
}

\author{
A. Perlade and R. Jacolot
}

ArcelorMittal, R\&D Automotive Products, Voie Romaine, 57283 Maizières-lès-Metz Cedex, France e-mail: astrid.perlade@arcelormittal.com

\section{Key words:}

austenite; dislocation density; flow stress; rolling loads prediction

Received 27 November 2013 Accepted 13 January 2014

\begin{abstract}
A model has been developed to describe the rheology of austenite at high temperatures, characteristic from hot strip rolling of low-alloyed steels. It is based on the evolution of a single dislocation density through storage and strain rate-dependent dynamic recovery. The model gives good predictions of the stress-strain curves in a wide range of temperatures, strain rates and chemical compositions. It is now applied on industrial hot strip mills to predict the rolling loads of a wide range of industrial steels.
\end{abstract}

\section{Introduction}

Current work is performed in ArcelorMittal to develop a microstructural model for the prediction of the austenite microstructure of conventional and micro-alloyed steels during multi-pass hot rolling. The objectives of this "computer metallurgy" are double:

- When coupled with a process model, it will enable the prediction of the rolling loads and the dimensional feasibility of our products under development.

- Prediction of the austenite state at the end of the rolling is also a key input for subsequent phase transformations and precipitation modelling. This work is thus part of an overall project to model the microstructural evolution and mechanical properties of ultra-high strength steels from the reheating furnace to the coil.

This article focuses on a new model for the description of the flow behaviour during deformation. This model is a part of a more global model which also describes metallurgical phenomena occurring during the inter-pass [1].

\section{Austenite behaviour}

Recently, improvements have been brought to the description of the rheology of austenite at high temperatures, taking into account

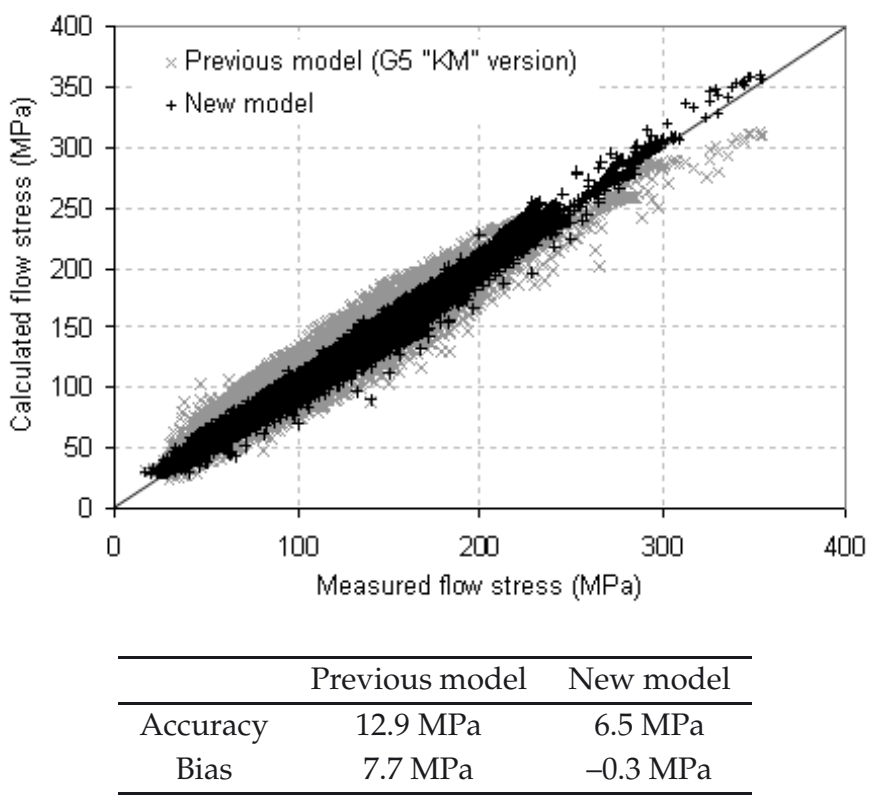

Fig. 1. Good overall accuracy of the flow stress prediction and improved compared to the previous approach.

the grain size effect, strain rate, temperature and chemistry effects. The model is based on the evolution of a single dislocation density through storage and strain rate-dependent dynamic recovery.

In the approach initially proposed by Bergström and developed by Laasraoui and Jonas [2], the work-hardening rate is assumed to vary linearly with $1 / \sigma$. 

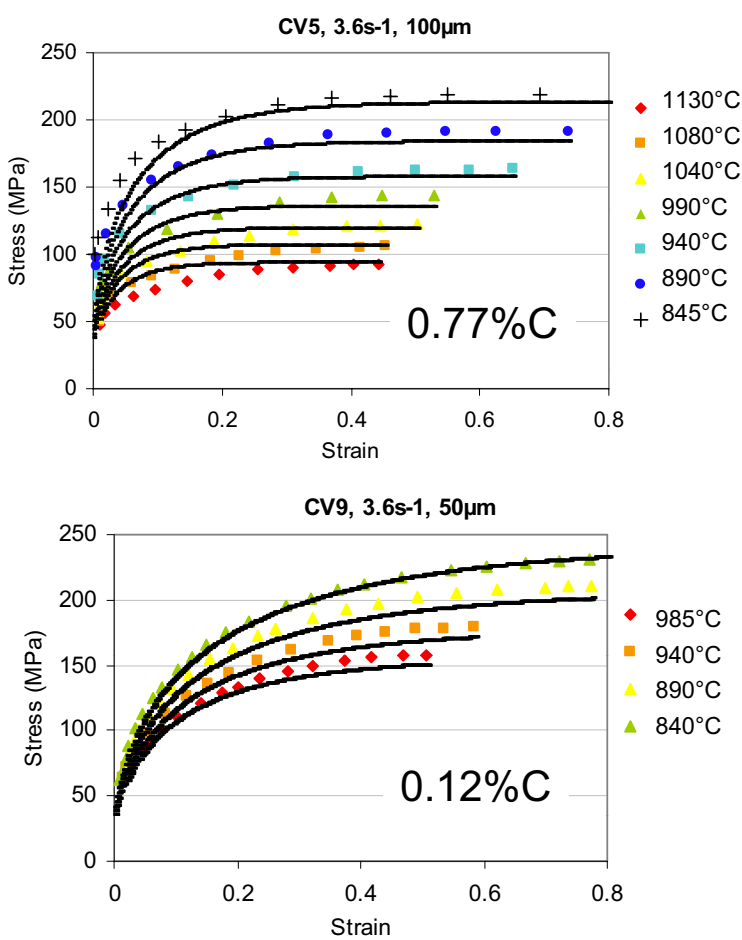

Fig. 2. The carbon level affects the strain hardening of austenite, which is well taken into account by the model (torsion data).

The evolution of the dislocation density with strain becomes of the form (1):

$$
\frac{d \rho}{d \varepsilon}=h-r \rho .
$$

Here, $h$ is a multiplication term and can be regarded as constant with respect to strain. The term $r \rho$ is the contribution due to dynamic recovery through dislocation annihilation and rearrangement.

This law showed to better reproduce strain hardening at large strains compared to the classical Kocks-Mecking equation [3] (too early stress saturation).

The present model has many advantages for modelling the flow behaviour of steels at high temperatures, particularly when compared to other existing models. It includes a saturation stress and describes the stress/strain curve accurately at a given strain rate and temperature using only two parameters. It was thus decided to use such an approach for the quantitative prediction of austenite flow behaviour at high temperatures.

In the case of a dual phase recrystallized/unrecrystallized microstructure, the

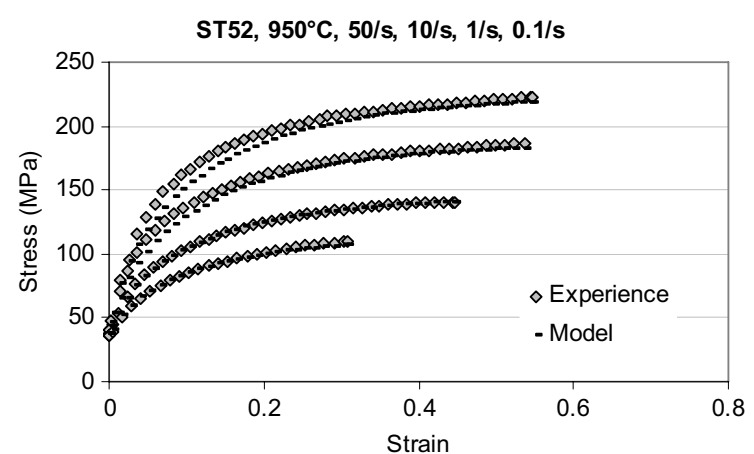

Fig. 3. Effect of strain rate is also well reproduced (uniaxial compression data, $0.2 \% \mathrm{C}, 1.5 \% \mathrm{Mn}, 0.2 \% \mathrm{Si}$ grade deformed at $950{ }^{\circ} \mathrm{C}$ for strain rates varying from 0.1 to $50 \mathrm{~s}^{-1}$ ).

model describes the evolution of the dislocation density in each phase and the total flow stress is determined using:

- a linear mixture law in terms of the volume fractions of recrystallized and unrecrystallized austenite;

- a same mixture law applied to the strains;

- the condition of equal plastic work increment in each constituent called IsoW proposed by reference [4].

\section{Results}

The different coefficients of the model were fitted on two experimental databases (20 different grades):

- One obtained by uniaxial compression on the high speed press on three groups of steels, with strain rate varying from $0.1 \mathrm{~s}^{-1}$ to $100 \mathrm{~s}^{-1}$, temperatures varying from $850{ }^{\circ} \mathrm{C}$ to $1050{ }^{\circ} \mathrm{C}$

- The other obtained by torsion simulations, on a wide range of grades (Carbon from $0.072 \mathrm{wt} \%$ to $0.77 \mathrm{wt} \%$ ), strain rate from $0.36 \mathrm{~s}^{-1}$ to $3.6 \mathrm{~s}^{-1}$ and temperatures from $840{ }^{\circ} \mathrm{C}$ to $1130{ }^{\circ} \mathrm{C}$.

The coefficients of the model were determined by a numerical optimization in order to minimize difference between experimental and modelled flow stresses.

The model gives good predictions of the stress-strain curves in a wide range of temperatures $\left(800{ }^{\circ} \mathrm{C}\right.$ to $\left.1150{ }^{\circ} \mathrm{C}\right)$, strain rates $\left(0.1 \mathrm{~s}^{-1}\right.$ to $\left.100 \mathrm{~s}^{-1}\right)$ (Fig. 3) and chemical compositions (from IF to $0.77 \%$ C) (Fig. 2). 


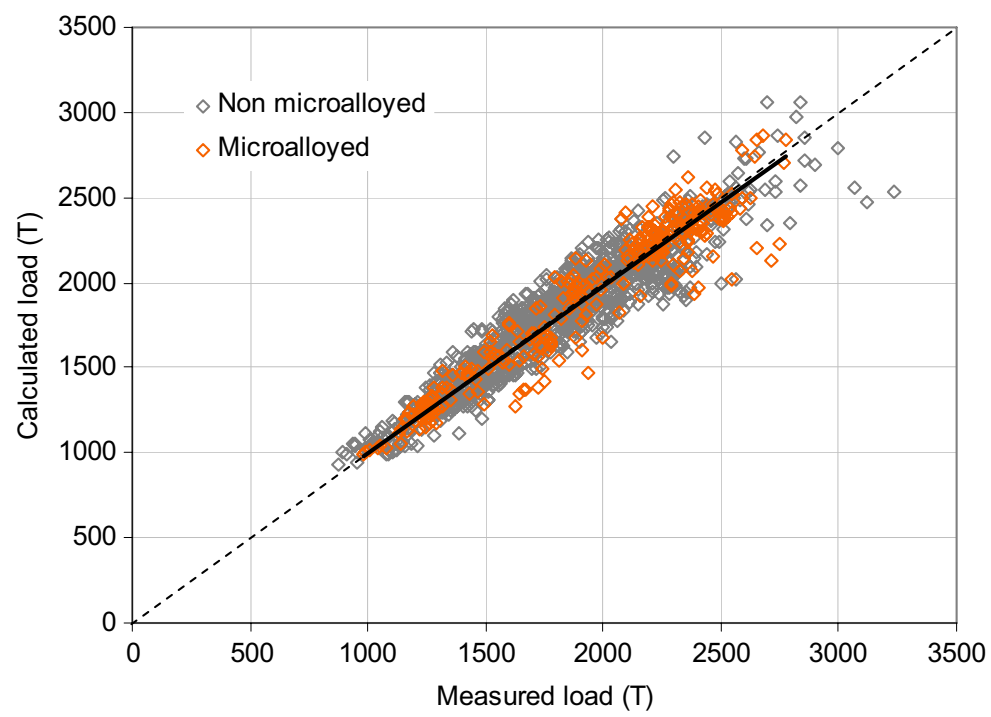

Fig. 4. Good agreement between calculated and measured loads, as measured on the second stand of an industrial finishing mill.

The effect of carbon content on the strain hardening is also well reproduced.

\section{Process application}

In the frame of global improvement of the finishing mill process, the present model has been coupled to the Orowan friction approach. Such a fast, robust and physical model has been applied to accurately predict the rolling loads of a wide range of industrial products (Fig. 4).

\section{References}

[1] A. Perlade, D. Grandemange, D. Huin, A. Couturier, K. Oostsuka, La Revue de Métallurgie - CIT (2008) 443-451

[2] A. Laasraoui, J.J. Jonas, Metall. Trans. A 22A (1991) 1545

[3] U.F. Kocks, J. Eng. Mater. Technol. 98 (1976) 76

[4] O. Bouaziz, P. Buessler, Adv. Eng. Mater. 6 (2004) 79-83

[5] U.F. Kocks, J. Eng. Mater. Technol. 98 (1976) 76 